\title{
Antioxidant and Antibacterial Activities of Exopolysaccharides Produced by Lactic Acid Bacteria Isolated from Yogurt
}

\author{
Zouaoui Benattouche ${ }^{\mathrm{a}^{*}}$, Djillali Bouhadi ${ }^{\mathrm{b}}$, And Ghalem Bachir RahO ${ }^{\mathrm{c}}$ \\ ${ }^{\mathrm{a}}$ Laboratory of Bioconversion, Microbiology Engineering and Alimentary Security, Department of Biology \\ Mascara University - 22900 Algeria \\ ${ }^{\mathrm{b}}$ Laboratory of Bioconversion, Microbiology Engineering and Alimentary Security, Department of Biology \\ Mascara University- 22900 Algeria \\ ${ }^{\mathrm{c}}$ Laboratoire de Microbiologie Moléculaire Proteomics et Santé, Department of Biology Sidi Belabbes \\ University- 22300 Algeria \\ ${ }^{*}$ Corresponding author \\ benattouche_22@yahoo.fr \\ TEL: +213557172691 \\ FAX: +21349646312
}

Received: 19 July 2017; Published online: 18 October 2018

\begin{abstract}
The objectives of this study were to optimize the conditions for cell growth and exopolysaccharides (EPS) production by using pure and mixed microbial cultures of Streptococcus thermophilus and Lactobacillus bulgaricus, and to evaluate the antioxidant and antibacterial activities of EPS in vitro. The mixed cultures of two strains showed a higher cell growth whereas the higher EPS production was detected in pure culture with $S$. thermophilus. The optimal medium were determined as follows $(\mathrm{g} / \mathrm{l})$ : sucrose 50, yeast extract $10, \mathrm{KH}_{2} \mathrm{PO}_{4} 3, \mathrm{MgSO}_{4} .7 \mathrm{H}_{2} \mathrm{O} 0.05$ and $\mathrm{pH}$ initial 6.5 at $30{ }^{\circ} \mathrm{C}$. Under the optimized conditions, the values of dry cell weight (DCW) and EPS were $5.2 \pm 0.8 \mathrm{~g} / \mathrm{l}$ and $56.8 \pm$ $0.62 \mathrm{mg} / \mathrm{ml}$, respectively. The EPS demonstrated a positive antioxidant potential on DDPH radical scavenging. The agar diffusion assay showed that purified EPS exhibited antibacterial activities against tested pathogens such as Escherichia coli ATCC 250922 and Staphyloccocus aureus ATCC 250923 at $(62-1000) \mu \mathrm{g} / \mathrm{mL}$. In conclusion, EPS have an antioxidant activity and could have applications in the food industry.
\end{abstract}

Keywords: Xopolysaccharide; antioxidant and antibacterial activities; Streptococcus thermophilus; Lactobacillus bulgaricus

\section{Introduction}

Recently, lactic acid bacteria (LAB) have received attention for their exopolysaccharides (EPS) producing ability. A broad range of EPS from $\mathrm{LAB}$ with variable functionality can have a wide range of industrial application (Cerning \& Marshall, 1999) as gelling agents, biosurfactants, emulsifiers, viscosifiers (Poli, Anzelmo, \& Nicolaus, 2010) and biosorbents (de Oliveira Martins, de Almeida, \& Ferreira Leite, 2008) In addition,
EPS play important roles in human health owing to their antitumor, antioxidant, anti-ulcer and antibacterial activities (Kocharin, Rachathewee, Sanglier, \& Prathumpai, 2010; Liu, Chu, Chou, \& Yu, 2011) However, owing to the lack of expansive knowledge on EPS from food-associated LAB, EPS have remained largely underexploited. Fermentation is a very versatile process technology for producing value added products such as microbial biopolymers and since fermentation 
parameters have a high impact upon the viability and economics of the bioprocess, their optimization holds great importance for process development. Especially, microbial polysaccharide production is greatly influenced by fermentation conditions such as $\mathrm{pH}$, temperature, oxygen concentration and agitation as well as by the composition of the culture medium (Bryan, Linhardt, \& Daniels, 1986).

Yogurt is a fermented dairy product resulting from the symbiotic growth of Streptococcus thermophilus and Lactobacillus bulgaricus during milk fermentation. A classical yogurt starter culture produces a smooth viscous gel, with a desirable fermented product aroma and flavor polysaccharides derived from $S$. thermophilus and $L$. bulgaricus show large variation in composition, charge, spatial arrangement, rigidity and ability to interact with proteins. Furthermore no defining correlation between EPS concentration and viscosity has been established in studies to date (Welman \& Maddox, 2003). With the aim of increasing knowledge of the functional EPS from $\mathrm{LAB}$ in yogurt, we have isolated LAB from yogurt. Among the LAB, a crude EPS of $S$. thermophilus was obtained, optimized and examined for its antioxidant and antibacterial activities to find a functionally active EPS.

\section{Materials and Methods}

\subsection{Microorganisms}

Standard strains of E. coli (ATCC 25922) and Staphylococcus aureus (ATCC 25923) were used for determination of the antibacterial activity. Lactic acid bacteria were isolated from yogurt samples obtained within the Mascara regions of Algeria in 2017.

\subsection{Isolation of Lactic Acid Bacterial Strains with High EPS Production}

Three EPS producing strains were isolated by selective plating (from yogurt) on MRS Agar and anaerobic incubation at $37{ }^{\circ} \mathrm{C}$ for $48 \mathrm{~h}$. EPS producing colonies were evaluated by touching colonies with a sterile inoculating loop. The presence of ropy strands between the loop and the colony as the loop was slowly raised was considered EPS positive. The colonies were picked up and propagated in MRS broth for $24 \mathrm{~h}$. The EPS producing isolates were verified for gram positive and catalase negative rods and cocci. The purity of cultures were verified by spreading cultures on MRS agar, and repeating several times until a pure culture was obtained.

The two EPS producing isolates were revived by transferring $0.5 \mathrm{ml}$ of each frozen stock to $10 \mathrm{ml}$ of MRS broth and incubating at $37{ }^{\circ} \mathrm{C}$ for $48 \mathrm{~h}$. The revived cultures were reactivated again by transferring $1.0 \mathrm{ml}$ to $10 \mathrm{ml}$ MRS broth and incubating at $37^{\circ} \mathrm{C}$ for $48 \mathrm{~h}$. The reactivated cultures were used as standard inoculums culture. In this experiment, the highest EPS producing isolates (S. thermophi-lus and L. bulgaricus), were used for EPS production in MRS broth. MRS was used as the EPS production media.

\subsection{Growth and EPS Production}

Lactic acid bacteria candidates ( $S$. thermophilus and $L$. bulgaricus) were isolated from yogurt and used after selection and identification according to Bergey's Manual of determinative bacteriology, 9th edition (Holt, Krieg, Sneath, Staley, \& Williams, 1994) and confirmation of identification by the anlaytical profile index (API) system. Pure and mixed cultures of the strains were tested for cell growth and production of exoplysaccharides. The pure and mixed microbial cultures were inoculated with a ratio of $1 \%(\mathrm{v} / \mathrm{v})$ into $100 \mathrm{ml}$ MRS broth in $500 \mathrm{ml}$ conical flasks in triplicate. The $\mathrm{pH}$ was adjusted to 6.5. The flasks were incubated on a rotary shaker at room temperature for $72 \mathrm{hrs}$. The exopolysaccharides were precipitated by adding 3 volumes of cold absolute ethanol and stored overnight at $4^{\circ} \mathrm{C}$. Finally, the recovered precipitates were redissolved with distilled water and dialyzed against the same solution for $24 \mathrm{~h}$ at $4{ }^{\circ} \mathrm{C}$ (Garcia-Garibay \& Marshall, 1991). The total amount of carbohydrates in the polysaccharides was determined by the phenoland sulfuric acid method described by (Dubois, Gilles, Hamilton, Rebers, \& Smith, 1956). The exopolysaccharides production was

\begin{tabular}{l|l|l|l} 
IJFS & October 2018 & Volume 7 & pages 30-37
\end{tabular} 
expressed as $\mathrm{mg} / \mathrm{ml}$ and biomass dry weight (g/l) was monitored by measuring the D600nm of the culture in the final fermented samples.

\subsection{Optimization of exopolysaccharide production}

To study the effect of different parameters, $1 \%$ inoculum containing $3.10^{8} \mathrm{UFC} / \mathrm{ml}$ were inoculated in $100 \mathrm{ml}$ of production medium. EPS production was optimized under different environmental and nutritional conditions viz incubation period (1 to 3 days), carbon sources (glucose, sucrose), nitrogen sources (peptone, yeast extract) and different sucrose concentrations $(1,2,3,4,5$ and $6 \%$ )

\subsection{Measurement of growth}

The optical density at $620 \mathrm{~mm}$ was used to monitor cell growth after appropriate dilution of samples (Adebayo-Tayo \& A. Onilude, 2008). Growth was measured as the dry weight per volume by centrifugation (5000 g for $10 \mathrm{~min}$ ) and then dried to a constant weight in an oven at 60 ${ }^{\circ} \mathrm{C}$ overnight to obtain cell dry weight (CDW).

\subsection{Determination of total carbohydrate content}

Total carbohydrate content was determined by the method of (Dubois et al., 1956). To the dried pellet, $1 \mathrm{~mL}$ of $5 \%$ phenol and $5 \mathrm{~mL}$ of $96 \%$ concentrated sulfuric acid was added and the mixture was kept in a boiling water bath for $20 \mathrm{~min}$. The optical density of the sample was read spectrophotometrically at $490 \mathrm{~nm}$ and total carbohydrate content was calculated, using glucose as the standard.

\subsection{Antibacterial activity of exopolysaccharides}

The disk diffusion method was used to determine antibacterial activity by quantifying the clear zone of inhibition around the filter paper disk. In this method, the autoclaved filter paper discs were impregnated with $50 \mu \mathrm{l}$ of the EPS and positioned on a nutrient agar plate, seeded with the test organisms, namely E. coli ATCC 25922 and $S$. aureus ATCC 25923. Penicillin, Gentamicin and Colistin were used as a positive control, while distilled water was used as a negative control. After firm placement of the discs, the plates were incubated at $37{ }^{\circ} \mathrm{C}$ in an inverted position for 1-2 days to allow different species of bacteria to grow. The zones of inhibition in discs were measured by a millimeter scale (Bauer, Kirby, Sherris, \& Turck, 1966).

\subsection{Free Radical Scavenging Activity}

The antioxidant activity was determined by the DPPH scavenging assay (Khalaf, Shakya, AlOthman, El-Agbar, \& Farah, 2008). Various concentrations $(62.5,125,250,500$ and 1000 $\mathrm{\mu g} / \mathrm{mL}$ ) of EPS were prepared in separate tubes. Ascorbic acid was used as a reference compound $(0.3125,0.625,1.25,2.5$ and $5.0 \mathrm{mg} / \mathrm{mL})$. A freshly prepared solution of $0.002 \%$ DPPH (2, 2, Diphenyl-2-Picryl hydrazyl) in methanol was added to each tube containing different concentrations of extracts $(2.0 \mathrm{~mL})$. The samples were incubated in the dark at $37{ }^{\circ} \mathrm{C}$ for $20 \mathrm{~min}$ and read at $515 \mathrm{~nm}$. The data were expressed as the percent decrease in the absorbance compared to the control. The percentage inhibition of radical scavenging activity was calculated.

\subsection{Statistical analysis}

The experiments were carried out in triplicate and results are given as the mean \pm standard deviation. The data in all the experiments were analysed (Microsoft Excel 2007) for statistical significance using the Student's Test, and differences were considered significant at $\mathrm{p}<0.05$. 


\section{Results and Discussion}

\subsection{Isolation of Lactic Acid Bacterial Strains with High EPS Production}

In this study, fifty strains of LAB were isolated from yogurt for determination of EPS production. The primary characterization of bacterial isolates indicated that they were gram positive, rods and cocci, catalase negative and anaerobic. All isolates were screened for EPS production in MRS broth, under anaerobic conditions at $37^{\circ} \mathrm{C}$ for $48 \mathrm{~h}$ as the EPS production period. According to their efficiency for EPS produc-tion, all but two isolates were in two categories namely high and weak, with respec-tive EPS concentrations from 1 to $10 \mathrm{~g} / \mathrm{l}$ and 0.1 to $1 \mathrm{~g} / \mathrm{l}$. 30 and 18 of these isolates were in the respective weak and high categories. Two out of the bacterial isolates from two different yogurts EPS (from 10 to over $25 \mathrm{~g} / \mathrm{l}$ ). These two isolates were subjected to complete identification using the API 20 System. They were identified as lactic acid bacterial strains L. bulgaricus and S. thermophilus.

\subsection{Growth and EPS Production Kinetics}

\section{Growth Intensity}

Dry cell weight (DCW) of the pure bacterial isolates of L.. Bulgaricus, S. thermophilus and mixed cultures in MRS broth for $72 \mathrm{~h}$ are presented in Figure. 1. During the first $20 \mathrm{~h}$ of the incubation period growth intensity in MRS medium increased for all three tested cultures. It was observed that the highest intensity (DCW $=$ $10.8 \pm 0.3 \mathrm{~g} / \mathrm{l}$ ) was recorded after $48 \mathrm{~h}$ by mixed cultures of $L$. bulgaricus and $S$. thermophilus followed by pure cultures of $L$. bulgaricus (DCW = $5.4 \pm 0.42 \mathrm{~g} / \mathrm{l}$ ) and pure cultures of $S$. thermophilus $(\mathrm{DCW}=4.6 \pm 0.8 \mathrm{~g} / \mathrm{l})$. After 48 to $72 \mathrm{~h}$ of incubation period the growth intensity in MRS medium decreased for all tested cultures. In addition, during $20-48 \mathrm{~h}$ of the incubation period there was a symmetric growth intensity for the strains grown in MRS broth.

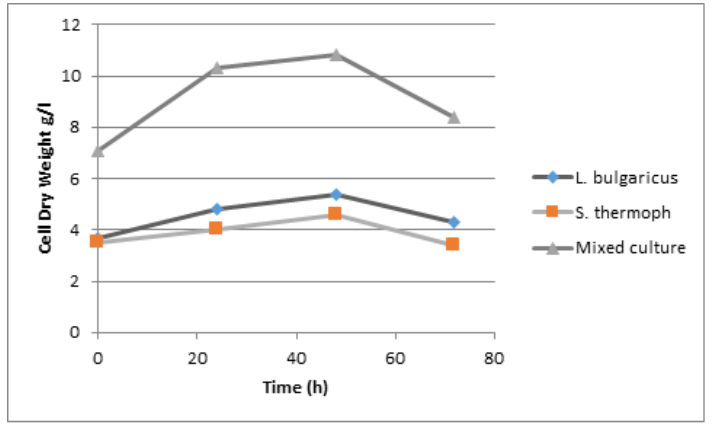

Figure 1: Cell dry weight of isolates of three cultures

\section{EPS production}

EPS production from the pure bacterial isolates of L. bulgaricus, S. thermophilus and mixed cultures grown in MRS broth at $37{ }^{\circ} \mathrm{C}$ for $72 \mathrm{~h}$ are presented in Figure 2 .The highest EPS production and EPS yield \% were achieved at 48 hours of growth. The pure cultures of $S$. thermophilus gave the highest EPS concentrations $(8.54 \pm 0.22$ $\mathrm{g} / \mathrm{l})$, followed by mixed cultures, and then the pure cultures of L. bulgaricus. The pure cultures of $S$. thermophilus were isolated, maitained on nutrient agar, and used throughout the study.

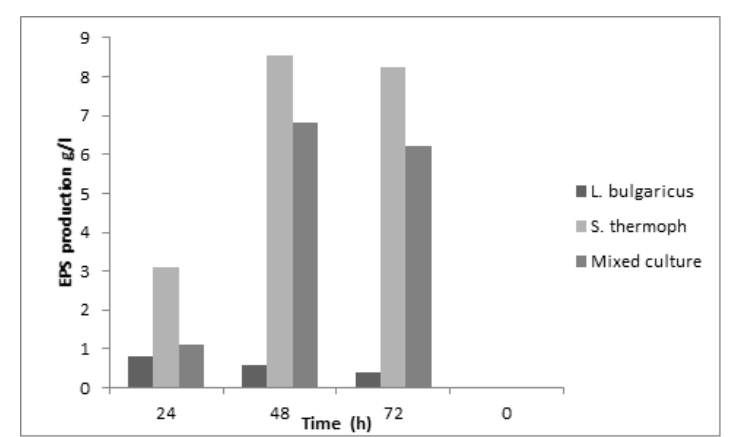

Figure 2: Exopolysaccharide content obtained from isolates of three cultures 


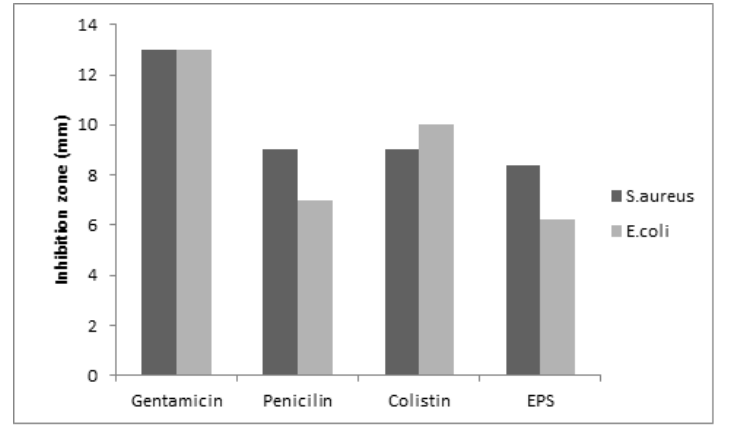

Figure 3: Agar-well diffusion test results of EPS and antibiotics

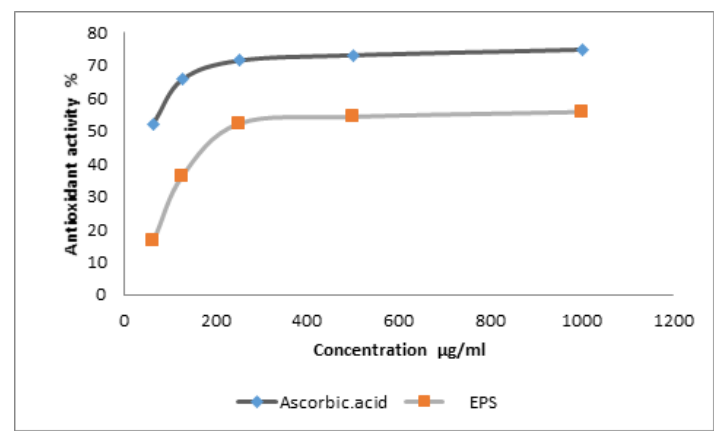

Figure 4: Antioxidant activity of different concentrations of EPS and ascorbic acid in DPPH radical scavenging method

\subsection{Optimization of exopolysaccharides}

The exopolysaccharide production of $S$. thermophilis was optimized under different environmental and nutritional conditions (Table 1). EPS production was determined during different periods of incubation (1, 2, and 3 days), and was highest after 2 days $(8.54 \pm 0.22 \mathrm{~g}$ EPS/L). Carbohydrates are the most abundant biomolecule and an important nutrient for cell growth and development (Zhang, Zhang, Li, Zhang, \& Yang, 2011). The effects of different carbon sources on the production of EPS were studied. In this study, it was found that sucrose was a suitable carbon source (Table 1). However, Antonio Mata et al. (2006) reported that glucose was a suitable carbon source for
EPS production. In this study, a $5 \%$ sucrose concentration in the medium gave higher EPS production $(56.8 \pm 0.62 \mathrm{~g} / \mathrm{l})$. Added peptone and yeast extract, as nitrogen sources, had negligible effect on EPS production $(56.8 \pm 0.62$ $\mathrm{g} / \mathrm{l})$.

\subsection{Antibacterial Activity}

Figure 3 shows the antimicrobial activity of purified EPS as evaluated by the disc diffusion method. Purified EPS inhibited the growth of $S$. aureus ATCC 25923 and E. coli ATCC 25922. Antimicrobial activity was maximum when 1000 $\mu \mathrm{g} / \mathrm{ml}$ of EPS were used and occurred after 72 $\mathrm{h}$ of incubation. The highest and lowest antimicrobial activities of purified EPS were 8.6 - 8.4 $\mathrm{mm}$ against $S$. aureus ATCC 25923, and 5.0 $6.2 \mathrm{~mm}$ against $E$. coli ATCC 25922 respectively. Purified polysaccharides had a lower inhibitory effect on growth in comparison with antibiotics frequently used for the treatment of infectious bacteria, such as Gentamicin, Penicillin and Colistin.

The shown sensitivity of gram-positive bacteria to polysaccharides extracts agrees with previous studies (Venturini, Rivera, Gonzalez, \& Blanco, 2008). This is due to the membrane composition of the bacterial stains (Holst \& Müller-Loennies, 2007). It has been reported that EPS from microorganisms have a strong antimicrobial activity against several pathogens in vitro, and several possible antibacterial mechanisms of EPS have been proposed, such as impairment of cell division, disruption of the cell wall and cytoplasmic membrane, and decomposition of DNA (He, Yang, Yang, \& Yu, 2010; Wu et al., 2010). According to these results, the antimi-crobial activity increased with increasing concentration of EPS.

\subsection{Antioxidant activity of EPS}

Antioxidant activities have been attributed to various reactions and mechanisms. In this study, the in vitro antioxidant activities of EPS from $S$. thermophi-lus were evaluated using the DPPH radical scavenging assay, and compared with ascorbic acid as a control. The antioxidant activ- 
Table 1: Optimization of exopolysaccharide production by $S$. thermophilus

\begin{tabular}{cccc}
\hline Parameter & Values & EPS g/l & Biomass gr/l \\
\hline Incubation period (days) & 1 & $3.10 \pm 0.3$ & $4.01 \pm 0.64$ \\
& 2 & $8.54 \pm 0.22$ & $4.6 \pm 0.8$ \\
& 3 & $8.26 \pm 0.12$ & $3.4 \pm 0.21$
\end{tabular}

Carbon source \%

\begin{tabular}{lccc} 
Glucose & 0.5 & $8.54 \pm 0.22$ & $4.6 \pm 0.8$ \\
Sucrose & 0.5 & $16.02 \pm 0.12$ & $4.2 . \pm 0.24$ \\
& & & \\
Sucrose concentration \% & 1 & $17.4 \pm 0.32$ & $4.7 \pm 0.62$ \\
& 2 & $26.6 \pm 0.24$ & $4.8 \pm 0.31$ \\
& 3 & $33.4 \pm 0.46$ & $4.8 \pm 0.6$ \\
& 4 & $37.2 \pm 0.17$ & $4.9 \pm 0.2$ \\
& 5 & $56.8 \pm 0.62$ & $5.2 \pm 0.8$ \\
& 6 & $51.2 \pm 0.6$ & $5.2 \pm 0.22$ \\
Nitrogen source \% & & & \\
peptone & 0.5 & $56.8 \pm 0.62$ & $5.2 \pm 0.5$ \\
yeast extract & 0.5 & $56.8 \pm 0.62$ & $5.6 \pm 0.8$ \\
\hline
\end{tabular}

Each value is expressed as mean $\pm \mathrm{SD}$

ities of purified EPS at different con-centrations $(62.5,125,250,500$ and $1000 \mu \mathrm{g} / \mathrm{ml})$ are shown in Figure. 4. The highest antioxidant activity of $55.83 \%$ was found for purified EPS at a concentration of $1000 \mu \mathrm{g} / \mathrm{ml}$, followed by those at $500 \mu \mathrm{g} / \mathrm{ml}(54.34 \%), 250 \mu \mathrm{g} / \mathrm{ml}(52.24 \%), 125$ $\mu \mathrm{g} / \mathrm{ml}(36.12 \%)$, and $62.5 \mu \mathrm{g} / \mathrm{ml}(16.34 \%)$. In the in vitro antioxidant assay, the purified EPS had a DPPH radical-scavenging activity, with an IC50 value of $225 \mu \mathrm{g} / \mathrm{ml}$.which was much higher than that of the standard antioxidant ascorbic acid $(48 \mu \mathrm{g} / \mathrm{mL})$.

The bioactivities of polysaccharides can be affected by many factors including chemical components, molecular weight, structure, conformation, and even the extraction and purification methods. The molecular weight of polysaccharides could play an important role in the antioxidant activity (Chen, Zhang, Qu, \& Xie, 2008).

\section{Conclusions}

In conclusion, the results of this study indicated that the extracellular polysaccharides (EPS) from lactic acid bacteria in yogurt have a significant antioxidant activity in the DPPH system. EPS could be used as antioxidative agents in the food industry.

\section{Acknowledgements}

The authors thank the Management of Mascara University for providing laboratory facilities and constant encouragement for this research work.

\section{References}

Adebayo-Tayo, B. \& A. Onilude, A. (2008). Screening of lactic acid bacteria strains isolated from some nigerian fermented foods for eps production. 4 . 
Antonio Mata, J., Bejar, V., Llamas, I., Arias, S., Bressollier, P., Tallon, R., ... Quesada, E. (2006). Exopolysaccharides produced by the recently described halophilic bacteria halomonas ventosae and halomonas anticariensis. Research in Microbiology, 157(9), 827-835. doi:10.1016/j.resmic.2006.06.004

Bauer, A. W., Kirby, W. M. M., Sherris, J. C., \& Turck, M. (1966). Antibiotic susceptibility testing by a standardized single disk method. American Journal of Clinical Pathology, 45(4), 493-496.

Bryan, B. A., Linhardt, R. J., \& Daniels, L. (1986). Variation in composition and yield of exopolysaccharides produced by klebsiella sp strain-k32 and acinetobactercalcoaceticus-bd4. Applied and Environmental Microbiology, 51(6), 1304-1308.

Cerning, J. \& Marshall, V. M. E. (1999). Exopolysaccharides produced by the dairy lactic acid bacteria. Recent Results and Developments, 3, 195-209.

Chen, H., Zhang, M., Qu, Z., \& Xie, B. (2008). Antioxidant activities of different fractions of polysaccharide conjugates from green tea (camellia sinensis). Food Chemistry, $106(2), 559-563$. doi:10.1016/j.foodchem. 2007.06 .040

de Oliveira Martins, P. S., de Almeida, N. F., \& Ferreira Leite, S. G. (2008). Application of a bacterial extracellular polymeric substance in heavy metal adsorption in a co-contaminated aqueous system. Brazilian Journal of Microbiology, 39(4), 780-786.

Dubois, M., Gilles, K. A., Hamilton, J. K., Rebers, P. A., \& Smith, F. (1956). Colorimetric method for determination of sugars and related substances. Analytical Chemistry, 28(3), 350-356. doi:10.1021/ac60111a017

Garcia-Garibay, M. \& Marshall, V. M. E. (1991). Polymer production by lactobacillus delbrueckii ssp. bulgaricus. Journal of Applied Microbiology, 70(4), 325-328.

He, F., Yang, Y., Yang, G., \& Yu, L. (2010). Studies on antibacterial activity and antibacterial mechanism of a novel polysaccharide from streptomyces virginia h03. Food Control, 21(9), 1257-1262. doi:10 . 1016/j.foodcont.2010.02.013
Holst, O. \& Müller-Loennies, S. (2007). Microbial polysaccharide structures. In J. P. Kamerling (Ed.), (Chap. Comprehensive glycoscience. From chemistry to systems biology, Vol. 1.04, pp. 123-133). Elsevier.

Holt, J. G., Krieg, N. R., Sneath, P. H. A., Staley, J. T., \& Williams, S. T. (1994). Bergey's manual of determinative bacteriology, 9th Ed. Baltimore (Williams \& Wilkins, Eds.).

Khalaf, N. A., Shakya, A. K., Al-Othman, A., ElAgbar, Z., \& Farah, H. (2008). Antioxidant activity of some common plants. Turkish Journal of Biology, 32(1), 51-55.

Kocharin, K., Rachathewee, P., Sanglier, J.-J., \& Prathumpai, W. (2010). Exobiopolymer production of ophiocordyceps dipterigenabcc 2073: optimization, production in bioreactor and characterization. $B M C$ Biotechnology, 10(1), 51. doi:10.1186/ 1472-6750-10-51

Liu, C.-T., Chu, F.-J., Chou, C.-C., \& Yu, R.-C. (2011). Antiproliferative and anticytotoxic effects of cell fractions and exopolysaccharides from lactobacillus casei 01. Mutation Research-genetic Toxicology and Environmental Mutagenesis, 721 (2), 157-162. doi:10.1016/j.mrgentox.2011.01.005

Poli, A., Anzelmo, G., \& Nicolaus, B. (2010). Bacterial exopolysaccharides from extreme marine habitats: production, characterization and biological activities. Marine Drugs, 8(6), 1779-1802. doi:10 . 3390 / md8061779

Venturini, M. E., Rivera, C. S., Gonzalez, C., \& Blanco, D. (2008). Antimicrobial activity of extracts of edible wild and cultivated mushrooms against foodborne bacterial strains. Journal of Food Protection, 71(8), 17011706. doi:10.4315/0362-028X-71.8.1701

Welman, A. \& Maddox, I. (2003). Exopolysaccharides from lactic acid bacteria: perspectives and challenges. Trends in Biotechnology, 21(6), 269-274. doi:10.1016 / S0167 7799(03)00107-0

Wu, M.-H., Pan, T.-M., Wu, Y.-J., Chang, S.-J., Chang, M.-S., \& Hu, C.-Y. (2010). Exopolysaccharide activities from probiotic bifidobacterium: immunomodulatory effects (on j774a.1 macrophages) and antimicrobial properties. International Jour- 
Antioxidant and Antibacterial Activities of Exopolysaccharides from Lactic Acid Bacteria $\mid 37$

nal of Food Microbiology, 144(1), 104-110.

doi:10.1016/j.ijfoodmicro.2010.09.003

Zhang, T., Zhang, C., Li, S., Zhang, Y., \& Yang, Z. (2011). Growth and exopolysaccharide production by streptococcus thermophilus st1 in skim milk. Brazilian Journal of Microbiology, 42(4), 1470-1478. doi:10.1590/ S1517-83822011000400033 